\title{
HUBUNGAN POLA NUTRISI DENGAN KEJADIAN STUNTING PADA BALITA DI DESA SOCAH KECAMATAN SOCAH KABUPATEN BANGKALAN MADURA
}

\author{
*Taufan Citra Darmawan \\ *STIKES William Booth SurabayaEmail : Tp4n_thefujin@yahoo.com
}

\begin{abstract}
ABSTRAK
Pemberian nutrisi balita yang kurang atau buruk di seribu hari pertama kehidupannya dapat berdampak pada konsekuensi yang irreversibel, yaitu kondisi dimana pertumbuhan terhambat atau stunting dapat terjadi pada seseorang. Tujuan dilakukan penelitian ini untuk mengetahui hubungan pola nutrisi dengan kejadian stunting pada balita di Desa Socah Kecamatan Socah Kabupaten Bangkalan Madura. Jenis penelitian ini menggunakan analitik observasional dengan desain penelitian case control. Populasi penelitian ini sebanyak 99 balita. Sampel penelitian ini 80 balita dibagi menjadi 2 kelompok yaitu 40 kelompok kasus dan 40 kelompok kontrol. Teknik sampling dalam penelitian ini menggunakan purposive sampling. Analisis data dilakukan dengan uji ChiSquare.Hasil penelitian yang didapatkan dari 80 balita, bahwa balita dengan pola nutrisi baik sebanyak 47 balita $(58,7 \%)$ dan balita dengan pola nutrisi tidak baik sebanyak 33 balita $(41,3 \%)$. Sedangkan kejadian stunting pada balita didapatkan balita tidak stunting sebanyak 40 balita (50\%) dan balita stunting sebanyak 40 balita (50\%). Hasil uji Chi-Square nilai $p=0,000$. Nutrisi pada balita bisa menyebabkan kurangnya asupan anak yang berdampak pada tidak adekuatnya sel dalam berkembang hingga menyebabkan terjadinya stunting.
\end{abstract}

\section{Kata Kunci: Balita, Pola Nutrisi, Stunting}

\begin{abstract}
Giving nutrition to toddlers that less or bad in the first thousand days of its living can give impact in irreversible consequence that is a condition where its growth are hampered or known as stunting. The purpose of this research is to determine the relation between nutrition patterns and stunting condition toward toddlers in Socah Village, Bangkalan - Madura. This research uses analytic observational with control case research design. The population in this research is 99 toddlers. The sample of this research is 80 toddlers that divided into two groups; 40 toddlers in case group and the rest in control group. Sampling technique in this research is purposive sampling. Data analysis is done by Chi-Square test. The result of the research from 80 toddlers is that toddlers with good nutrition system are 47 person $(58,7 \%)$ and toddlers with bad nutrition system are 33 person $(41,3 \%)$. Whereas for stunting condition toward toddlers, there is $40(50 \%)$ persons do not get stunting condition and $40(50 \%)$ persons who get stunting condition. The result of Chi-Square test are the value of $p=0,000$. The conclusion of this research is toddlers who examine hamperedgrowth are caused by the lack of adequate nutrition fulfillment and the increase of metabolic needs that decrease the appetite. It can increase the lack of nutrition toward toddlers. This condition is difficult to resolve growth disorder that gives opportunity to stunting condition.
\end{abstract}

Keywords: Nutrition Patterns, Stunting, Toddler 


\section{PENDAHULUAN}

Masa balita termasuk dalam periode emas untuk pertumbuhan dan perkembangan anak. Masa balita yaitu masa pergantian, terutama saat anak berada pada rentang 1-2 tahun, makan-makanan padat, rasa dan tekstur makanan yang baru mulai diberikan pada balita. Anak tumbuh dan berkembang dengan cepat saat balita hingga dibutuhkan asupan nutrisi yang lebih banyak. Nutrisi yang baik serta seimbang mempunya efek pada tumbuh kembang anak khususnya otak. seribu hari pertama kehidupan anak adalah masa penting yang mempunyai efek pada konsekuensi yang irreversibel, sehingga bila terganggu berdampak pada stunting. Oleh karena itu, dibutuhkan asupan nutrisi balita dari berbagai sumber dan makanan (Agria, 2012).

UNICEF data 2000-2007 menunjukkan prevalensi kejadian stunting di dunia mencapai $28 \%$, dimana kejadian tertinggi di afrika timur dan selatan yang mencapai $40 \%$ dari anak yang dilahirkan (UNICEF, 2009).

Indonesia merupakan salah satu negara yang cukup tinggi kejadian stuntingnya. Riskesdas tahun 2013 menunjukkandata di Indonesia 7,6 juta balita tergolong stunting $37,2 \%$ jika dibandingkan tahun $2010(35,6 \%)$ dan tahun 2007 (36,8\%) tidak ditunjukkan penurunan/perbaikan signifikan (Kemenkes RI, 2013). Menurut hasil PSG tahun 2015, kejadian stunting di Provinsi Jawa Timur sebesar $27,1 \%$ diantaranya $17,6 \%$ pendek dan 9,5\% sangat pendek. Menurut Unicef Nations International Children's EmergencyFund (UNICEF) satu dari tiga anak mengalami stunting. 4 dari 10 anak di pedesaan mengalami gangguan pertumbuhan

Berdasarkan survei awal yang dilakukan peneliti terhadap 10 balita di Desa Socah Kecamatan Socah Kabupaten Bangkalan Madura melalui wawancara dengan ibu yang mempunyai balita dan observasi tinggi badan balita sesuai umur, didapatkan $6(60 \%)$ balita yang tinggi badannya tidak sesuai umur karena dari keluarga yang ekonominya rendah yang berdampak pada pemberian nutrisi pada balita. Sedangkan $4(40 \%)$ balita lainnya memiliki tinggi badan sesuai umur dan kebanyakan dari keluarga yang ekonominya cukup untuk membeli makanan yang beragam pada balita.

Stunting adalah suatu keadaan dimana tinggi badan anak yang terlalu rendah.
Stunting atau terlalu pendek berdasarkan umur adalah tinggi badan yang berada dibawah minus dua standar deviasi $(<-2 \mathrm{SD})$ dari tabel status gizi WHO child growth standard (WHO, 2012). Tinggi badan anak yang berada dibawah minus dua standar deviasi (<-2SD) tergolong stunting (pendek), status gizi anak dikategorikan pendek berdasarkan indeks antropometri tinggi badan berdasarkan umur. Kondisi ini umumnya terjadi karena kebutuhan nutrisi yang tidak terpenuhi sejak bayi, bahkan sejak dalam kandungan (Supartini, 2004).

Dampak nutrisi pada anak yang terlihat jelas adalah terhadap pertumbuhan fisik. Setiap balita memiliki potensi genetik untuk pertumbuhan fisik, mental, dan emosional. Nutrisi yang optimal dapat dicapai dengan diberikannya gizi yang memenuhi semua kebutuhan potensial pertumbuhan tersebut. Umeta (2003). Penelitian Nurul (2011) dapat diketahui bahwa nutrisi memegang peranan penting dalam pola perkembangan dan pertumbuhan anak. Penelitian Arifin dkk (2012), kurangnya asupan gizi beresiko 2,6 kali lebih besar terjadinya stunting dibandingkan balita dengan gizi baik.

Kejadian stunting pada balita terjadi akibat asupan nutrisi yang kurang pada balita. Untuk mendapatkan asupan nutrisi yang cukup diperlukan makanan yang baik, sehat dan bergizi karena penting untuk balita agar bisa tumbuh dan berkembang dengan optimal.Oleh karena itu, tentukan makanan yang tepat pada balita, tentukan jumlah kebutuhan dari setiap nutrien, kemudian tentukan jenis bahan makanan yang dapat dipilih untuk diolah sesuai dengan menu yang diinginkan, tentukan juga jadwal pemberian makanan dan perhatikan porsi yang dihabiskannya (Supartini, 2004).

Berdasarkan penjelasan diatas maka peneliti tertarik untuk melakukan penelitian yang berjudul "hubungan pola nutrisi dengan kejadian stunting pada balita di Desa Socah Kecamatan Socah Kabupaten Bangkalan Madura".

\section{BAHAN DAN METODE}

Metode observasi analitik diberlakukan dalam penelitian ini dengan design case control yang mengukur tentang faktor resiko dengan pendekatan retrospektif untuk mengukur status nutrisi anak balita 
Studi case controldilakukan dengan mengindentifikasi kelompok kasus dan kelompok kontrol, kemudian secara retrospektif (penelusuran kebelakang) diteliti faktor-faktor resiko yang mungkin dapat menerangkan apakah kasus dan kontrol dapat terkena paparan atau tidak.

Desain penelitian ini yang digunakan dalam kelompok kasus yaitu balita yang mengalami stunting dan yang termasuk dalam kelompok kontrol adalah balita yang tidak mengalami stuntingdi Desa Socah Kecamatan Socah Kabupaten Bangkalan Madura

Sampel dalam penelitian yaitu balita di Desa Socah Kecamatan Socah Kabupaten Bangkalan MaduraDari 80 balita akan dibagi menjadi 2 kelompok yaitu 40 balita sebagai kelompok kasus dan 40 balita sebagai kelompok kontrol. Teknik sampling yang digunakan dalam penelitian ini adalah purposive sampling.

HASIL.

Karakteristik Responden berdasarkan Umur Ibu

Tabel Distribusi Responden berdasarkan Umur Ibu di Desa Socah Kecamatan Socah Kabupaten Bangkalan Madura Bulan Mei 2018

\begin{tabular}{cccc}
\hline No & $\begin{array}{c}\text { Umur } \\
\text { (tahun) }\end{array}$ & $\begin{array}{c}\text { Jumlah } \\
(\mathbf{n})\end{array}$ & $\begin{array}{c}\text { Presentase } \\
(\mathbf{\%})\end{array}$ \\
\hline 1. & $<20$ & 0 & 0 \\
2. & $20-35$ & 60 & 75 \\
3. & $>35$ & 20 & 25 \\
\hline \multicolumn{2}{c}{ Total } & 80 & 100 \\
\hline
\end{tabular}

Sumber: Data Primer, 2018

Tabel di atas menunjukkan bahwa dari 80 responden, sebagian besar berumur 20-35 tahun sebanyak 60 responden $(75 \%)$ dan sebagian kecil berumur $>35$ tahun sebanyak 20 responden $(25 \%)$.

\section{Karakteristik Responden berdasarkan Pendidikan Ibu}

TabelDistribusi Responden berdasarkan Pendidikan Ibu di Desa Socah Kecamatan Socah Kabupaten Bangkalan Madura Bulan Mei 2018

\begin{tabular}{cccc}
\hline No & Pendidikan & $\begin{array}{c}\text { Jumlah } \\
\text { (n) }\end{array}$ & $\begin{array}{c}\text { Presentase } \\
\text { (\%) }\end{array}$ \\
\hline 1. & SD & 35 & 43,8 \\
2. & SMP & 14 & 17,5 \\
3. & SMA & 19 & 23,7
\end{tabular}

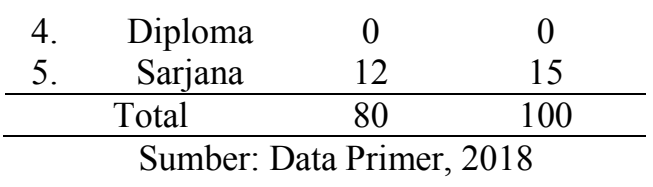

Tabel di atasmenunjukkan bahwa dari 80 responden, sebagian besar berpendidikan SD sebanyak 35 responden $(43,8 \%)$ dan sebagian kecil berpendidikan Sarjana sebanyak 12 responden $(15 \%)$.

$\begin{array}{lrr}\text { Karakteristik } & \text { Responden } & \text { berdasarkan } \\ \text { Pekerjaan Ibu } & & \\ \text { TabelDistribusi } & \text { Responden } & \text { berdasarkan }\end{array}$ Pekerjaan Ibu di Desa Socah Kecamatan Socah Kabupaten Bangkalan Madura Bulan Mei 2018

\begin{tabular}{cccc}
\hline No & Pekerjaan & $\begin{array}{c}\text { Jumlah } \\
(\mathbf{n})\end{array}$ & $\begin{array}{c}\text { Presentase } \\
(\%)\end{array}$ \\
\hline 1. & Bekerja & 22 & 27,5 \\
2. & $\begin{array}{c}\text { Ibu } \\
\text { Rumah } \\
\text { Tangga }\end{array}$ & 58 & 72,5 \\
\hline & Total & 80 & 100 \\
\hline
\end{tabular}

Sumber: Data Primer, 2018

Tabel di atasmenunjukkan bahwa dari 80 responden, sebagian besar responden adalah Ibu Rumah Tangga sebanyak 58 responden $(72,5 \%)$ dan sebagian kecil responden bekerja sebanyak 22 responden $(27,5 \%)$.

\section{Data Khusus}

Data khusus menampilkan data tentang identifikasi pola nutrisi pada balita, identifikasi kejadian stunting pada balita, serta menganalisis hubungan pola nutrisi dengan kejadian stunting pada balita.

\section{Pola Nutrisi}

Tabel Distribusi Balita berdasarkan Pola Nutrisi di Desa Socah Kecamatan Socah Kabupaten Bangkalan Madura Bulan Mei 2018

\begin{tabular}{cccc}
\hline No & $\begin{array}{c}\text { Pola } \\
\text { Nutrisi }\end{array}$ & $\begin{array}{c}\text { Jumlah } \\
\text { (n) }\end{array}$ & $\begin{array}{c}\text { Presentase } \\
\text { (\%) }\end{array}$ \\
\hline 1. & $\begin{array}{c}\text { Pola } \\
\text { nutrisi } \\
\text { baik }\end{array}$ & 47 & 58,7 \\
& $\begin{array}{c}\text { Pola } \\
\text { nutrisi } \\
\text { tidak }\end{array}$ & 33 & 41,3 \\
\hline
\end{tabular}




\begin{tabular}{ccc} 
baik & & \\
\hline Total & 80 & 100 \\
\hline
\end{tabular}

Sumber: Data Primer, 2018

Tabel di atasmenunjukkan bahwa dari 80 balita, sebagian besar balita dengan pola nutrisi baik sebanyak 47 balita $(58,7 \%)$ dan sebagian kecil balita dengan pola nutrisi tidak baik sebanyak 33 balita $(41,3 \%)$.

Tabel Distribusi Pola Nutrisi Balita berdasarkan Makanan Pokok di Desa Socah Kecamatan Socah Kabupaten Bangkalan Madura Bulan Mei 2018

\begin{tabular}{cccc}
\hline No & $\begin{array}{c}\text { Makanan } \\
\text { Pokok }\end{array}$ & $\begin{array}{c}\text { Jumlah } \\
(\mathbf{n})\end{array}$ & $\begin{array}{c}\text { Presentase } \\
(\mathbf{\%})\end{array}$ \\
\hline 1. & Nasi & 80 & 100 \\
2. & Jagung & 0 & 0 \\
3. & Singkong & 0 & 0 \\
4. & Kentang & 0 & 0 \\
5. & Ketela & 0 & 0 \\
6. & Mie & 0 & 0 \\
7. & Roti & 0 & 0 \\
\hline & Total & 80 & 100 \\
\hline
\end{tabular}

Sumber: Data Primer, 2018

Tabel di atasmenunjukkan bahwa dari 80 balita, sebagian besar balita mengkonsumsi makanan pokok jenis nasi sebanyak 80 balita $(100 \%)$.

TabelDistribusi Pola Nutrisi Balita berdasarkan Lauk Pauk Hewani di Desa Socah Kecamatan Socah Kabupaten Bangkalan Madura Bulan Mei 2018

\begin{tabular}{|c|c|c|c|}
\hline No & $\begin{array}{c}\text { Lauk } \\
\text { Pauk } \\
\text { Hewani }\end{array}$ & $\begin{array}{c}\text { Jumlah } \\
\text { (n) }\end{array}$ & $\begin{array}{c}\text { Presentase } \\
\quad(\%)\end{array}$ \\
\hline 1. & $\begin{array}{l}\text { Daging } \\
\text { sapi }\end{array}$ & 4 & 5 \\
\hline 2. & $\begin{array}{c}\text { Daging } \\
\text { ayam }\end{array}$ & 8 & 10 \\
\hline 3. & $\begin{array}{l}\text { Telur } \\
\text { ayam }\end{array}$ & 47 & 58,7 \\
\hline 4. & $\begin{array}{l}\text { Telur } \\
\text { puyuh }\end{array}$ & 2 & 2,5 \\
\hline 5. & Ikan & 14 & 17,5 \\
\hline 6. & Udang & 5 & 6,3 \\
\hline & Total & 80 & 100 \\
\hline
\end{tabular}

Sumber: Data Primer, 2018

Tabel di atasmenunjukkan bahwa dari 80 balita, sebagian besar balita mengkonsumsi lauk pauk hewani jenis telur ayam sebanyak 47 balita $(58,7 \%)$ dan sebagian kecil balita mengkonsumsi lauk pauk hewani jenis telur puyuh sebanyak 2 balita (2,5\%).

Tabel Distribusi Pola Nutrisi Balita berdasarkan Lauk Pauk Nabati di Desa Socah
Kecamatan Socah Kabupaten Bangkalan Madura Bulan Mei 2018

\begin{tabular}{|c|c|c|c|}
\hline No & $\begin{array}{c}\text { Lauk } \\
\text { Pauk } \\
\text { Nabati }\end{array}$ & $\begin{array}{c}\text { Jumlah } \\
\text { (n) }\end{array}$ & $\begin{array}{c}\text { Presentase } \\
(\%)\end{array}$ \\
\hline 1. & Tahu & 15 & 18,7 \\
\hline 2. & Tempe & 65 & 81,3 \\
\hline 3. & $\begin{array}{c}\text { Kacang } \\
\text { tanah }\end{array}$ & 0 & 0 \\
\hline 4. & $\begin{array}{c}\text { Kacang } \\
\text { hijau }\end{array}$ & 0 & 0 \\
\hline \multicolumn{2}{|c|}{ Total } & 80 & 100 \\
\hline
\end{tabular}

Sumber: Data Primer, 2018

Tabel di atasmenunjukkan bahwa dari 80 balita, sebagian besar balita mengkonsumsi lauk pauk nabati jenis tempe sebanyak 65 balita $(81,3 \%)$ dan sebagian kecil balita mengkonsumsi lauk pauk nabati jenis tahu sebanyak 15 balita (18,7\%).

Tabel Distribusi Pola Nutrisi Balita berdasarkan Sayuran di Desa Socah Kecamatan Socah Kabupaten Bangkalan Madura Bulan Mei 2018

\begin{tabular}{cccc}
\hline No & Sayuran & $\begin{array}{c}\text { Jumlah } \\
\text { (n) }\end{array}$ & $\begin{array}{c}\text { Presentase } \\
(\%)\end{array}$ \\
\hline 1. & Bayam & 32 & 40 \\
2. & Kangkung & 0 & 0 \\
3. & Wortel & 27 & 33,7 \\
4. & Kacang & 13 & 16,3 \\
5. & kanjang & 8 & 10 \\
\hline & Total & 80 & 100 \\
\hline
\end{tabular}

Sumber: Data Primer, 2018

Tabel di atasmenunjukkan bahwa dari 80 balita, sebagian besar balita mengkonsumsi sayuran jenis bayam sebanyak 32 balita (40\%) dan sebagian kecil balita mengkonsumsi sayuran jenis kubis sebanyak 8 balita (10\%).

TabelDistribusi Pola Nutrisi Balita berdasarkan Buah-buahan di Desa Socah Kecamatan Socah Kabupaten Bangkalan Madura Bulan Mei 2018

\begin{tabular}{cccc}
\hline No & $\begin{array}{c}\text { Buah- } \\
\text { buahan }\end{array}$ & $\begin{array}{c}\text { Jumlah } \\
(\mathbf{n})\end{array}$ & $\begin{array}{c}\text { Presentase } \\
\mathbf{( \% )}\end{array}$ \\
\hline 1. & Pisang & 59 & 73,7 \\
2. & Pepaya & 12 & 15 \\
3. & Semangka & 5 & 6,3 \\
4. & Melon & 1 & 1,3 \\
5. & Kelengkeng & 3 & 3,7 \\
\hline & Total & 80 & 100 \\
\hline
\end{tabular}

Sumber: Data Primer, 2018 
Tabel di atasmenunjukkan bahwa dari 80 balita, sebagian besar balita mengkonsumsi buah-buahan jenis pisang sebanyak 59 balita $(73,7 \%)$ dan sebagian kecil balita mengkonsumsi buah-buahan jenis melon sebanyak 1 balita (1,3\%).

\section{Kejadian Stunting}

TabelDistribusi Balita berdasarkan Kejadian Stunting di Desa Socah Kecamatan Socah Kabupaten Bangkalan Madura Bulan Mei 2018

\begin{tabular}{|c|c|c|c|}
\hline No & $\begin{array}{c}\text { Kejadian } \\
\text { Stunting }\end{array}$ & $\begin{array}{c}\text { Jumlah } \\
\text { (n) }\end{array}$ & $\begin{array}{c}\text { Presentase } \\
(\%)\end{array}$ \\
\hline 1. & $\begin{array}{c}\text { Tidak } \\
\text { stunting }\end{array}$ & 40 & 50 \\
\hline 2. & Stunting & 40 & 50 \\
\hline & Total & 80 & 100 \\
\hline
\end{tabular}

Sumber: Data Primer, 2018

Tabel di atasmenunjukkan bahwa dari 80 balita, balita tidak stunting sebanyak 40 balita $(50 \%)$ dan balita stunting sebanyak 40 balita $(50 \%)$.

\section{Hubungan Pola Nutrisi dengan Kejadian Stunting pada Balita}

TabelHubungan Pola Nutrisi dengan Kejadian Stunting pada Balita di Desa Socah Kecamatan Socah Kabupaten Bangkalan Madura Bulan Mei 2018

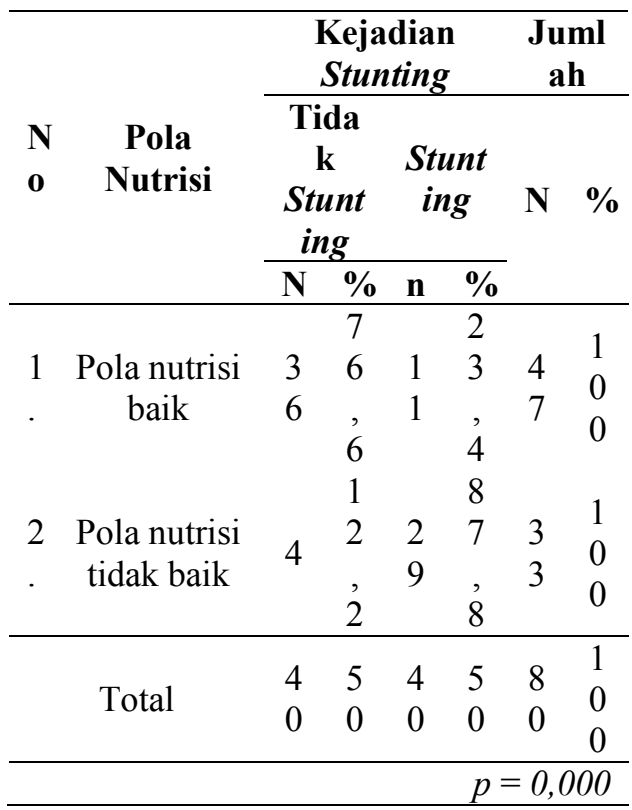

Sumber: Data Primer, 2018

Tabel di atasmenunjukkan bahwa balita dengan pola nutrisi baik dan tidak stunting sebanyak 36 balita $(76,6 \%)$, balita dengan pola nutrisi baik dan stunting sebanyak 11 balita $(23,4 \%)$. Sedangkan balita dengan pola nutrisi tidak baik dan tidak stunting sebanyak 4 balita $(12,2 \%)$, balita dengan pola nutrisi tidak baik dan stunting sebanyak 29 balita $(87,8 \%)$.

\section{Hasil Uji Statistik}

Berdasarkan hasil perhitungan menggunakan SPSS versi 22.00 dengan tingkat kesalahan $\alpha(0,05)$. Didapatkan hasil uji statistik menggunakan uji Chi-Square diperoleh hasil yang signifikan $p=0,000<\alpha=0,05$. Dengan hasil demikian maka $\mathrm{H}_{1}$ diterima dan $\mathrm{H}_{0}$ ditolak, yang berarti ada hubungan pola nutrisi dengan kejadian stunting pada balita di Desa Socah Kecamatan Socah Kabupaten Bangkalan Madura.

\section{PEMBAHASAN}

Berdasarkan hasil penelitian yang dilakukan peneliti menunjukkan bahwa balita dengan pola nutrisi baik dan tidak stunting sebanyak 36 balita $(76,6 \%)$, balita dengan pola nutrisi baik dan stunting sebanyak 11 balita $(23,4 \%)$. Sedangkan balita dengan pola nutrisi tidak baik dan tidak stunting sebanyak 4 balita $(12,2 \%)$, balita dengan pola nutrisi tidak baik dan stunting sebanyak 29 balita $(87,8 \%)$.

Berdasarkan hasil perhitungan menggunakan SPSS versi 16.00 dengan tingkat kesalahan $\alpha(0,05)$. Didapatkan hasil uji statistik menggunakan uji Chi-Square diperoleh hasil yang signifikan $p=0,000<\alpha=0,05$. Dengan hasil demikian maka $\mathrm{H}_{1}$ diterima dan $\mathrm{H}_{0}$ ditolak, yang berarti ada hubungan pola nutrisi dengan kejadian stunting pada balita di Desa Socah Kecamatan Socah Kabupaten Bangkalan Madura.

Sesuai dengan teori bahwa dalam keadaan asupan nutrisi yang baik dan sehat (seimbang) pertumbuhan seorang anak akan normal. Sebaliknya bila anak dalam keadaan nutrisi kurang seimbang maka pertumbuhan anak akan terganggu seperti anak pendek, kurus, dan gemuk. Masalah kurang nutrisi pada balita masih cukup tinggi, salah satunya karena kualitas makanan sebagian besar masyarakat Indonesia terutama pada anak balita yang masih belum bergizi seimbang sehingga akan berdampak kekurangan asupan 
nutrisi yang salah satunya stunting (Depkes, 2007).

Beberapa ahli berpendapat bahwa malnutrisi kronis sama dengan stunting. Ini berarti anak penderita malnutrisi kronis akan mengalami stunting, tetapi anak yang stunting tidak semuanya kekurangan nutrisi. Balita mengalami stunting karena tidak menerima perawatan yang cukup dari ibu mereka, terutama yang berkenaan dengan makanan. Sebagai akibat rendahnya tingkat pendidikan ibu, atau karena adanya kecenderungan para ibu untuk mengabaikan masalah pola nutrisi (Soetjiningsih, 2010).

Balita yang menderita stunting disebabkan karena kurang asupan nutrisi dan pola nutrisi yang tidak baik. Faktor genetik atau keturunan bukan penyebab utama balita terkena stunting. Akan tetapi, anak balita tersebut selama masa kehidupan 1000 hari sejak kehamilannya atau setara balita usia 2 tahun, kurang mendapat asupan nutrisi dan pola nutrisi yang baik. Meski faktor gen (genetik/turunan) memang mempengaruhi stunting, persentasinya sangat kecil hanya $5 \%$. Selebihnya karena faktor asupan nutrisi dan pola nutrisi balita (Nashikah, 2012). Hal ini sesuai dengan penelitian yang dilakukan Berlina Dwi (2014) menyatakan bahwa terdapat hubungan antara pola pemberian nutrisi dengan status gizi balita pada usia 3-5 tahun Di Dusun Dempok Utara Desa Grogol Kecamatan Diwek Kabupaten Jombang.

Praktek pemberian makan pada anak sangat penting dan besar pengaruhnya bagi pertumbuhan anak. Memberikan suasana yang nyaman bagi anak pada saat makan, mengetahui selera makan yang baik pada anak, sabar dan penuh perhatian pada saat memberikan makan tentu dapat menjalin keakraban diantara keduanya sehingga diharapkan anak mampu menghabiskan makanan yang diberikan (Husaini, 2007). Menurut penelitian yang dilakukan Romeli (2007) menyebutkan bahwa anak balita yang pola makannya tidak baik, secara bermakna proporsinya lebih tinggi pada kelompok stunting dibandingkan kelompok tidak stunting. Pola makan berhubungan dengan pemenuhan kebutuhan nutrisi balita, yang artinya berkaitan pula dengan pola nutrisi balita.

Menurut peneliti, bahwa balita dengan pola nutrisi baik tidak mengalami stunting dan balita dengan pola nutrisi tidak baik mengalami stunting. Pola nutrisi balita yang baik diberikan orang tua sesuai dengan gizi seimbang. Baik buruknya pola nutrisi yang diberikan dapat memberikan dampak positif maupun negatif pada proses pertumbuhan balita. Kecukupan asupan nutrisi pada balita berpengaruh terhadap kondisi metabolik anak dimana gangguan dalam metabolik berpengaruh pada kondisi perkembangan anak yang mampu mengakibatkan stunting pada anak.

\section{SIMPULAN}

Di Desa Socah Kecamatan Socah Kabupaten Bangkalan Madura, sebagian besar balita dengan pola nutrisi baik sebanyak 47 balita $(58,7 \%)$. Di Desa Socah Kecamatan Socah Kabupaten Bangkalan Madura, balita tidak stunting sebanyak 40 balita $(50 \%)$ dan balita stunting sebanyak 40 balita (50\%).Ada hubungan pola nutrisi dengan kejadian stunting pada balita di Desa Socah Kecamatan Socah Kabupaten Bangkalan Madura $(p=0,000)$.

\section{DAFTAR PUSTAKA}

Aditianti., 2010. Faktor Determinan Stunting pada Anak Usia 24-59 Bulan di Indonesia. Tesis pada Program Studi Mayor Gizi Masyarakat. IPB Bogor.

Agria, R., 2012. Gizi Reproduksi. Yogyakarta: Fitamarya.

Alderman, H., dan Shekar, M., 2011. Nutrition, Food Security and Health. Philadelphia: Elsevier Saunders.

Almatsier, S., 2011. Prinsip Dasar Ilmu Gizi. Jakarta: Gramedia Pustaka Utama.

Allen, L., dan Gillespie, S., 2001. What Works? a Review of the Efficacy and Effectiveness of Nutrition Intervention. Nutrition Policy Paper.

Anisa, P., 2012. Faktor-faktor yang Berhubungan dengan Stunting pada Balita Usia 25-60 Bulan di Kelurahan Kalibaru Depok. Jakarta: Universitas Indonesia.

Ari, Y., 2008. Gizi dan Kesehatan. Yogyakarta: Graha Ilmu.

Arifin, D.Z., dkk., 2012. Analisis Sebaran dan Faktor Resiko Stunting pada Balita di Kabupaten Purwakarta. Epidemiologi Komunitas FKUP Bandung.

Arikunto, S., 2010. Prosedur PenelitianSuatu Pendekatan Praktik. Jakarta: Rineka Cipta. 
Astari, L.D., Nasoetion, A., dan Dwiriani, C.M., 2006. Hubungan Konsumsi ASI dan MP-ASI serta Kejadian Stunting Anak Usia 6-12 Bulan di Kabupaten Bogor. Skripsi. Bogor: Media Gizi dan Keluarga.

Berlina, Dwi dkk., 2014. Hubungan Pola Pemberian Nutrisi dengan Status Gizi Balita Usia 3-5 Tahun di Dusun Dempok Utara Desa Grogol Kecamatan Diwek Kabupaten Jombang. Program Studi D3 Kebidanan STIKES Pemkab Jombang.

Depkes., 2007. Penelitian Gizi dan Makanan. Jakarta: Pusat Penelitian dan Perkembangan Gizi.

Dewi, R.C., dkk. 2015. Teori dan Konsep Tumbuh Kembang Bayi, Toddler, Anak dan Usia Remaja. Yogyakarta: Nuha Medika.

Fitri., 2012. Berat Lahir Sebagai Faktor Dominan Terjadinya Stunting pada Balita (12-59 Bulan) di Sumatera (Analisi Data Riskesdas 2010). Thesis. Depok: FKM UI.

Gibney, M.J., et al. 2009. Gizi dan Kesehatan Masyarakat/Public Health Nutrition. Jakarta: Buku Kesehatan EGC.

Hardiansyah dan Tampubolon., 2004. Angka Kecukupan Energi, Protein, Lemak dan Serat Makanan. Jakarta: LIPI.

Henningham dan Mc Gregor. 2008. Public Health Nutrition. Jakarta: Kedokteran EGC.

Hidayah, N.R., 2011. Faktor-faktor yang Berhubungan dengan Kejadian Stunting pada Balita Usia 24-59 Bulan di Propinsi Nusa Tenggara Timur Tahun 2010 (Analisis Data Riskesdas 2010). Skripsi. Depok: FKM UI.

Hidayat, A., Aziz Alimul. 2015. Pengantar Kebutuhan Dasar Manusia Edisi 2. Jakarta: Salemba Medika.

Hidayat, T.S., dan Jahari, A., 2012. Perilaku Pemanfaatan Posyandu Hubungan Status Gizi dan Morbiditas Balita. Buletin Penelitian Kesehatan.

Hidayat, A., 2005. Pengantar Ilmu Keperawatan Anak 1. Jakarta: Salemba Medika.

Husaini, M.A., 2007. Peranan Gizi dan Pola Asuh dalam Meningkatkan Kualitas Tumbuh Kembang Anak. Jakarta: EGC.
Jauhari dan Nasution., 2013. Nutrisi dan Keperawatan Cetakan 1. Yogyakarta: Dua Satria Offset.

Kartikawati, P., 2011. Faktor yang Mempengaruhi Kejadian Stunted Growth pada Anak Balita di Wilayah Kerja Puskesmas Arjasa Kabupaten Jember. Skripsi. Jember: Fakultas Kesehatan Masyarakat Universitas Jembe 